\title{
A REPRESENTAÇÃO SOCIAL DO VÍNCULO FAMILIAR PELO IDOSO
}

\author{
THE SOCIAL REPRESENTATION OF THE FAMILIAR BOND BY THE SENIOR \\ LA REPRESENTACIÓN SOCIAL DEL VINCULO FAMILIAR POR EL ANCIANO
}

\author{
Márcia Regina Cubas* \\ Maria do Carmo Lisboa** \\ Maria Heloísa Madruga Chaves***
}

* Enfermeira, Mestre em Saúde Pública, Doutoranda em Enfermagem na Escola de Enfermagem da Universidade de São Paulo. Professora da
Pontifícia Universidade Católica do Paraná. e-mail: m.cubas@pucpr.br
** Enfermeira, Mestre em Educação, Professora da Pontifícia Universidade Católica do Paraná. e-mail: carminhalisboa@hotmail.com
*** Enfermeira, Mestre em Educação, Professora da Pontifícia Universidade Católica do Paraná.

RESUMO: O vínculo estabelecido entre o idoso e os outros membros da família facilita ou não a convivência familiar e a passagem tranqüila por esse ciclo vital. As representações sobre o processo de envelhecer num contexto de vínculo familiar na ótica do idoso potencializam a assistência prestada ao binômio idoso-família. O objetivo deste estudo é apresentar o discurso construído por um grupo de idosos sobre o vínculo familiar no processo de envelhecer. Trata-se de uma pesquisa qualitativa com abordagem social, utilizando a ferramenta metodológica do Discurso do Sujeito Coletivo. Os sujeitos da pesquisa foram oito idosos pertencentes a um grupo de terceira idade da região metropolitana de Curitiba/PR. O idoso reporta a família como uma formação humana indispensável, reconhece que a mesma está em constante "crises" e seu conceito vai além dos laços de consangüinidade; mostra-se preocupado com a subsistência familiar; são apontadas as presenças da institucionalização e da violência, sendo que a primeira não tem conotação negativa se vista como formadora de laços e a segunda merece um tratamento maior em face da complexidade do assunto que ainda é considerado um tabu. É premente afirmar que o trabalhar com família pressupõe vislumbrá-la como um processo contínuo, com a presença de contradições e que a compreensão de seus problemas e potencialidade mudará a cada novo contato e cada posição que a mesma se encontra no ciclo vital.

PALAVRAS-ChAVE: Família; Idoso; Saúde; Relações familiares.

ABSTRACT: The bond established between the senior citizens and the other members of family facilitates or not family relationships and the calm passage through this vital cycle. The representations of aging process in a familiar bond context in the view of the senior citizen strengthen the assistance given to the senior citizen and the family. The objective of this study is to present the senior citizens group speech about familiar bond in the aging process. It is a qualitative research whit social approach, using the "Speech of the Collective Citizen" methodology tool. A group of eight senior citizens from metropolitan region of Curitiba/Pr were the subjects of the research. The senior citizen reports the family as a vital human structure. Recognizes that the family is in constant crisis and its concept goes beyond blood bonds; he/she is worried about the family survival; violence and "institutionalization" are pointed out, the first one does not have a negative connotation if it's seen as an originator of bonds and second deserves further discussion given the complexity of the subject that still is considered a taboo. It is imperative to affirm that working with family involves seen it as a continuous process, with the presence of contradictions and that the understanding of its problems and potentiality will change at each new contact during the vital cycle.

KEYWORDS: Family; Aged; Health; Family relations.

RESUMEN: El vinculo que es establecido entre el anciano y los otros miembros de la familia facilita el convivió familiar y el pasaje tranquilo por este ciclo de vida. Las representaciones al proceso de envejecer en un contexto de helo familiar, en la visión del anciano, favorecen el cuidado que se da al dúo anciano-familia. El objetivo de este estudio es mostrar el discurso formado por un grupo de ancianos sobre el vinculo familiar durante el proceso de envejecimiento. Se trata de una pesquisa cualitativa con enfoque social, utilizando como herramienta del método el Discurso del Sujeto Colectivo. Los personajes de la pesquisa fueron ocho ancianos integrantes de un grupo de tercera edad de la región de Curitiba-PR. El anciano percebe la familia como una formación humana indispensable, reconoce que está en "crisis" constantemente y su idea va más allá que la consanguinidad familiar, apuntan la institucionalización y la violencia, siendo que la primera no tiene un matiz negativo, si vista como criadora de lazos y la segunda merece un otro tratamiento ya que la complejidad del asunto todavía la torna tabú. Es esencial decir que, trabajar con familia supone vislumbrarla como un proceso continuo, con presencia de contradicciones, que la comprensión de sus problemas y potencialidad mudará a cada nuevo contacto y a cada lugar que esta ocupe en el ciclo vital.

PALABRAS-CLAVE: Familia; Anciano; Salud; Relaciones familiares.

Recebido em: 24/11/2003

Aceito em: 09/02/2004
Maria Heloísa Madruga Chaves

Rua Sanito Rocha, 225 - Ap. 108 - 80050-380 - Curitiba - PR

E-mail: eloisachaves@uol.com.br. Tel: (41) 363-0889 


\section{INTRODUÇÃO}

As relações de convivência familiar e o estabelecimento de vínculos sociais constituem-se como indicadores relevantes na qualificação da condição de saúde da população idosa. Esta relação possibilita uma melhor qualidade de vida e maior capacidade de sobrevivência. ${ }^{1}$

O vínculo estabelecido entre o idoso e os outros membros da família facilita ou não a convivência familiar e a passagem tranqüila por esse ciclo vital que, como todos os outros ciclos contêm crises e adaptações. A dinâmica do sistema familiar cumpre importante papel no sentido da absorção das tensões provocadas pelos conflitos e mudanças presentes no processo de envelhecer, que requerem adaptações tanto do idoso quanto da sua família, que igualmente envelhece. ${ }^{2}$

A assistência ao idoso pressupõe a compreensão de sua inserção numa família em continuo processo de interação, cabendo ressaltar que os dados da PNAD (Pesquisa Nacional de Amostra Domiciliaria) apresentam que mais de 85\% dos idosos no Brasil vivem com suas famílias e apenas $11,6 \%$ sozinhos ou com pessoas sem laço de parentesco. ${ }^{1}$

Parece consenso que o funcionamento familiar está relacionado com a saúde da família e, em relação a famílias com idosos, deve-se lembrar que as funções familiares se modificam no sentido de fornecer respostas às necessidades dos idosos, modificações estas relacionadas à "garantia de satisfação das necessidades físicas e de conforto além de prover suporte emocional ao idoso, manutenção de uma ligação entre a família e a comunidade, a instilação de um senso de significado de vida e manejo das crises". ${ }^{2}$

O envelhecimento é um fenômeno natural e processual, e por mais que seja individual o ser humano vive na esfera coletiva e sofre influências da sociedade. Viver a velhice é a soma das características pessoais, vivenciais alegrias e frustrações. A velhice pode ser entendida como o resultado dos anos vividos, sendo sua qualidade relacionada à visão de mundo do indivíduo e da sociedade em que ele está inserido. ${ }^{3,4}$

De 1980 a 1999 a população idosa no Brasil cresceu $70 \%$, passando de 7,2 milhões para 12,6 milhões ${ }^{1}$ o que nos leva a crer na presença do idoso na sociedade e conseqüentemente no núcleo familiar que sofreu mudanças em seu ciclo vital devido à presença constante do idoso.

As famílias são sistemas complexos que necessitam de adaptação a evoluções biológicas, psicológicas, sociológicas e culturais muitos diferentes e ao mesmo tempo, portanto as tensões e mudanças contínuas produzidas pelas contradições entre estas evoluções são normais. Trabalhar com famílias pressupõe o entendimento destas contradições a partir da perspectiva do observador e do vínculo afetivo implícito na vida familiar. ${ }^{5}$

Vínculos se referem a laços emocionais exclusivos e resistentes, a manutenção deste laço é experimentada como fonte de segurança e sua renovação como fonte de alegria, “...muitas das mais intensas emoções surgem durante a formação, manutenção, ruptura de laços afetivos...". ${ }^{5}$ É importante ressaltar que não existe um vínculo certo ou errado ou um melhor ou pior, é preciso reconhecer que a idéia de vínculo na saúde da família ultrapassa o conceito dual, deve-se incluir os relacionamentos e as redes de contato, percebendo assim a definição de família não só como um agregado tradicional e restrito que utiliza critérios de consangüinidade, adoção e casamento, mas que família é quem seus membros dizem que são. ${ }^{5}$

Ao aproximar-se da interpretação que o idoso faz do vínculo familiar no processo de envelhecimento, leva-nos a utilizar o conceito de representação social para o entendimento deste fenômeno. "A representação social é sempre representação de alguma coisa (objeto) e de alguém (sujeito)... a representação social tem com o seu objeto uma relação de simbolização (substituindo-o) e de interpretação (conferindo-lhe significações)". ${ }^{6}$ Portanto, para conhecer o pensamento dos idosos sobre o vínculo familiar no 
processo de envelhecer, faz-se necessário conhecer seus discursos que são processados por suas crenças, opiniões e valores, ou seja, sua matéria discursiva coletiva, dando luz "ao conjunto de individualidades semânticas componentes do imaginário social". ${ }^{7}$

Face ao exposto estudar as representações sobre o processo de envelhecer num contexto de vínculo familiar na ótica do idoso potencializa a assistência prestada ao binômio idoso-família permitindo um cuidado focado na visão de quem esta vivenciando o processo de envelhecimento e não apenas centralizado na percepção profissional.

O objetivo deste estudo é apresentar o discurso construído por um grupo de idosos sobre o vínculo familiar no processo de envelhecer.

\section{METODOLOGIA}

O presente estudo faz parte de um projeto "guarda chuva" intitulado: "Perdas, Danos e Ganhos do Processo de Envelhecer" do grupo de pesquisa do Curso de Enfermagem da Pontifícia Universidade Católica do Paraná - PUCPR, denominado GESEC (Grupo de Estudos Articulando os Processos de Cuidado, Educação e Gerenciamento em Enfermagem). É um recorte da pesquisa sobre representação social do processo de envelhecer.

Trata-se de uma pesquisa qualitativa com abordagem social. Os sujeitos da pesquisa foram compostos por oito idosos pertencentes a um grupo de terceira idade da região metropolitana de Curitiba/ PR. Foi utilizado um roteiro de perguntas semiestruturado previamente aplicado. As entrevistas foram gravadas em fitas cassete e posteriormente transcritas literalmente. As questões éticas foram resguardadas pela aprovação do Comitê de Ética da PUCPR, além do consentimento livre e esclarecido por parte dos participantes da pesquisa, com base na resolução 196/96.

A técnica para organização dos dados foi o discurso do sujeito coletivo - DSC de Lefèvre e Lefèvre $^{7}$ cuja proposta é organizar e tornar mais claro uma dada representação social e o conjunto de representações, reunindo vários discursos obtidos em um único discurso síntese. A proposta consiste em analisar todo material verbal coletado tendo por base a aplicação das quatro figuras metodológicas: as expressões chaves $(\mathrm{ECH})$ - "são pedaços, trechos ou transcrições literais do discurso"7; as idéias centrais (IC) - a descrição sintética dos sentidos das expressões chaves; a ancoragem (AC) - 0 alicerce de pressupostos e teorias que sustentam a prática, referindo-se a "inserção do objeto da representação em um marco de referência préexistente" ligando um conhecimento novo a um outro já constituído8; e o DSC - a reunião num discurso síntese redigido na primeira pessoa do singular composto de expressões chaves que tenham a mesma idéia central e/ou ancoragem.

Os discursos foram ancorados e discutidos à luz da literatura sobre a atenção ao idoso no contexto familiar.

\section{RESULTADOS}

Os discursos construídos a partir da idéia central acerca do vínculo familiar direcionaram para três grandes linhas: o primeiro aponta para a importância da família como instituição; o segundo apresenta um sentimento do querer ajudar e o terceiro proporciona a idéia da presença de maus tratos aos idosos.

DSC 1- "Eu acho que a família é tudo, é a nossa vida. A minha família é muito boa, às vezes a gente até dá umas briguinhas, mas é pouco, acaba tudo em brincadeira. Não acontece aquela briga, discussões, daqui a pouco está todo mundo rindo e feliz. Meus filhos me dão muito carinho, são mais carinhosos comigo do que antes. É muito importante, não só os filhos e netos como os irmãos. Eu era solteira quando morei com minha tia e depois voltei para casa de minha mãe, depois minha tia dizia que quando eu saí de lá a casa tinha perdido a alegria, até 
hoje as filhas dela são ligadas comigo. Tem que levar em frente o valor da família que a gente tem, porque é uma só, acabou aquela, pronto! Depois de Deus, só eles. Primeiramente Deus, depois minha família".

DSC 2- "O mais importante da minha vida é estar do lado da minha família ajudando meus filhos e os netos. A gente tem muita vontade de ajudar. Do jeito que as coisas estão ruins, se eu fosse mais novo, ajudaria mais a minha família".

DSC 3 - "Tem idoso que sofre demais da conta, eu vejo alguns idosos sendo maltrados pela família. Às vezes eu vejo algumas famílias por aí, como podem ser tão desunidas? Esses que matam os pais... falta de amor... Era pai tinha que respeitar, se não se dá, saia de perto! Dependendo da família, o asilo é a família dele".

O primeiro discurso gerado pela idéia central de que "a família é tudo", é ancorado pela percepção do idoso da importância da relação familiar. A afirmação de que "Família é uma formação humana e universal, não tendo sido descoberta outra formação capaz de substituí-la"2 aporta parte deste discurso.

Outro ponto a ser ressaltado é o fato de que as famílias estão em constante processo de transformação mantendo-as em equilíbrio instável marcados pelas "crises" e o envelhecimento é considerado uma dessas crises no ciclo vital. $\mathrm{Na}$ intimidade de uma família amadurecida as suas funções serão mais estáveis quanto mais predisposição este grupo tiver para mudanças, aceitação do outro, comunicação e respeito ${ }^{2}$ e isso é verificado no imaginário social do idoso quando aponta a existência de "briguinhas", mas que "acaba tudo em brincadeira".

Acresce a ancoragem deste discurso às relações de manutenção de elos com outros núcleos familiares, principalmente os de origem, que permitem diálogos e ajuda. Isso constitui uma teia de relações com vínculos formados pelas relações afetivas e de proximidade, gerando manifestações de afeto, a necessidade de estar junto, a demonstração de admiração e respeito ${ }^{9,10}$. O que se observa quando o idoso fala sobre a importância não só da proximidade com os filhos e netos, mas, também, as dos irmãos, tios e primos.

A segunda fala construída a partir da idéia central da "vontade de ajudar" nos remete a reflexão acerca da mudança nas representações da velhice que ofertam a imagem da terceira idade como uma fase de experiências gratificantes, redefinindo valores, atitudes e comportamentos deste grupo, não a reconhecendo como uma fase do desenvolvimento que apresenta fragilidades e limitações ${ }^{11}$. Com esta imagem há o risco de responsabilizar o idoso pela sua condição, diminuindo as políticas sociais voltadas a este segmento, o fato do idoso sentir-se responsável pelo provimento familiar pode ser um fator desencadeado por este imaginário social.

A partir disso a aposentadoria, que deveria ser vista como um direito assegurado a todos os cidadãos, passa a ser uma forma de provimento para uma família que não apresenta renda suficiente para seu sustento e o idoso considera-se co-responsável pela subsistência da mesma.

O terceiro discurso apresentado sobre a idéia central de "dependo da família, o asilo é a família dele", nos faz refletir que as representações sobre a velhice atestam a presença de dramas expressos nas imagens de idosos em estado de abandono, em instituições asilares ${ }^{9}$. Porém, o que se verifica no discurso apresentado é que nem sempre o idoso percebe a instituição como um fator negativo, mas que este espaço pode ser visualizado como possibilitador de laços familiares, por meio da convivência oferecida nestes ambientes, que devem oferecer segurança e dignidade com regulação do Estado no sentido do cumprimento de normas para o seu funcionamento 4 .

Ainda neste discurso se expressa a questão sobre a violência à família, conseqüentemente ao 
idoso. É sabido que o fenômeno da violência tem sido apontado como um dos problemas mais desafiadores para a sociedade contemporânea, atingindo todas as faixas etárias indiscriminadamente, porém para a população idosa esta situação, entre outras, é reflexo dos conflitos de ordem social e relação de poder entre gerações ${ }^{12}$. Ressaltamos que a violência familiar é "omitida tanto pelo agressor como pelo agredido, levando a uma cumplicidade entre ambos, preservando desta forma a sacralidade da família"12.

Se analisarmos a importância que a população idosa manifesta em seu discurso sobre o vínculo familiar: "Depois de Deus, só eles", leva-nos a reflexão se os dados disponibilizados sobre a presença de violência ao idoso são reais ou apenas a ponta de um iceberg, escondendo de fato sua magnitude.

\section{CONSIDERAÇÕES FINAIS}

O modo de nomear e definir diferentes aspectos da realidade, interpretando-a para posteriormente tomar decisões é a forma de expressão das representações sociais. Conhecer a representação social de "algo" por "alguém" é de suma importância para o entendimento das práticas discursivas produzidas por um grupo, que partilham idéias afirmando um vínculo social e uma identidade. ${ }^{6}$

Portanto, estudar e refletir sobre o envelhecimento e sua relação com a família possibilitará não só a instrumentalização dos profissionais da saúde, mas também a elaboração de estratégias de educação em saúde para cuidadores familiares ${ }^{9}$ e deve ser considerado como uma ferramenta para potencializar o trabalho efetivo com a família.

Percebe-se no decorrer de nosso envolvimento com o grupo de idosos, que outro fator fundamental é a criação da consciência coletiva que o trabalho conjunto entre os grupos de idosos e os profissionais de saúde propicia a busca da conquista de cidadania. Para isso devemos compreender o imaginário daquele grupo em relação ao seu ciclo vital e ao conceito de vínculo familiar, sem o qual reproduziríamos uma prática prescritiva sob a nossa ótica e não pelo olhar de quem vivencia o processo de envelhecer.

No recorte apresentado, os discursos referem que o idoso vê a família como uma formação humana indispensável para seu bem estar, reconhece que a mesma está em constantes "crises" decorrentes das modificações do seu ciclo vital e seu conceito vai além dos laços de consangüinidade.

Outro fato relevante é que o idoso se mostra preocupado com a subsistência familiar, querendo "partilhar" de ajuda, principalmente financeira. Ainda são apontadas as presenças da institucionalização e da violência, sendo que a primeira não tem conotação negativa se vista como formadora de laços e a segunda merece um tratamento maior em face da complexidade do assunto que ainda é considerado um tabu levando-se em consideração: quem é o agressor e a importância da sacralidade da família.

É premente afirmar que o trabalhar com família pressupõe vislumbrá-la como um processo contínuo, com a presença de contradições e que a compreensão de seus problemas e potencialidade mudarão a cada novo contato e cada posição que a mesma se encontra no ciclo vital. Cabe ressaltar que não podemos esquecer que a família vive em uma estrutura social que estabelece interseções em seu funcionamento particular e, reconhecer a representação dos seus componentes destas interações e dos conceitos produzidos por elas é o diferencial para promover uma assistência com foco na necessidade familiar.

\section{REFERÊNCIAS}

1 Araújo TCN, Alves MIC. Perfil da População idosa no Brasil. In: Veras R e colaboradores. Velhice numa perspectiva de futuro saudável. Rio de Janeiro: UNATI; 2001, p. 99-114.

2 Duarte YAO, Cianciarullo TI. Idoso, família e saúde na família. In: Cianciarullo TI, Gualda DMR, Cunha ICKO, Silva GTR. Saúde na Família e na Comunidade. São Paulo: Robe; 2002, p. 231-67.

3 Brêtas ACP. Cuidadores de idosos e o sistema único de saúde. REBEn 2003; 56(3): 298-301. 
4 Beck CLC, Gonzalez RMB, Colomé ICS. Os desafios (im) postos pelo processo de envelhecimento humano.Rev Téc-cient Enferm 2003; 1(2): 122-6.

5 Wright LM, Leahey M. Enfermeiras e famílias: um guia para avaliação e intervenção na família.3. ed. São Paulo: Roca; 2002.

6 Jodelet D. Representações sociais: um domínio em expansão. In: Jodelet $D$, organizador. As representações sociais. Rio de Janeiro: EdUERJ; 2000. p.17-44.

7 Lefèvre $F$, Lefèvre AMC. O discurso do sujeito coletivo: um novo enfoque em pesquisa qualitativa (desdobramentos). Caxias do Sul, RS: EDUCS; 2003.

8 Andrade Júnior $\mathrm{H}$, Souza MA, Brochier JI. Representação social da educação ambiental e da educação em saúde em universitários. Psicologia: Reflexão e crítica 2004; 17(1): 43-50.
9 Althoff CR. Delineando uma abordagem teórica sobre o processo de conviver em família. In: Elsen I, Marcon SS, Santos MR. O viver em família e sua interface com a saúde e a doença. Maringá: Eduem; 2002. p. 25-44.

10 Freitas MC, Mendes MMR. O ensino sobre processo de envelhecimento e velhice nos cursos de graduação em enfermagem. REBEn 2003; 56(5): 502-7.

11 Creutzberg MS, Santos BRL. Famílias cuidadoras de pessoa idosa: relação com instituições sociais e de saúde. REBEn 2003, 56(6): 624-9.

12 Alves DCI, Silva LMH, Fernandes LM, Durman S. A violência no idoso. Nursing 2002; 5(47): 26-30. 